\title{
Change capability of protection systems
}

\author{
N. Gronau ${ }^{1}$, S. Sielaff ${ }^{2}$, E. Weber ${ }^{1}$, T. Roechert-Voigt ${ }^{1} \&$ M. Stein ${ }^{1}$ \\ ${ }^{1}$ Chair of Business Information Systems and Electronic Government, \\ University of Potsdam, Germany \\ ${ }^{2}$ Ministry of the Interior, Land Brandenburg, Germany
}

\begin{abstract}
The presented ongoing research project focuses on the protection of critical infrastructures. The aim is to improve the interaction in disaster management by designing change-capable protection systems. Change Capability describes the ability of a system to conform quickly and efficiently on changing requirements. The research results are tested by an impact assessment for disasters. This method is based on both technological and legal impact assessment. Within the practical part of the project, the current protection system of a chemical plant is analyzed scenario-based. Afterwards this system is explored again by the impact assessment with the improvements concerning the Change Capability. By comparing the consequences of a disaster scenario with and without change capable qualities, it is possible to verify the vantages of adaptable protection systems. The paper introduces the procedures for Change Capability analysis and for disaster impact assessment. Furthermore, the first results of the practical application are represented.
\end{abstract}

Keywords: change capability, critical infrastructures, protection systems, impact assessment.

\section{Introduction}

In our modern society disaster management and the protection of critical infrastructures need an integrated approach. Among the changes of the basic economic conditions which refer to privatisation, liberation and globalisation, the dependencies between infrastructures grow. Every part of public and private life is highly affected by complex and cross-linked infrastructures. Due to increasing risks like international terrorism, organised crime and natural disasters, critical 
infrastructures need a special protection effort. Damages and blackouts cause high impacts on the supply of necessary goods and services and on the public security. It has to be considered that critical infrastructures do not end at frontiers but are cross-linked regarding regional and international dependencies.

The actions of operators of critical infrastructures, public authorities and aid organisations in an emergency have essential influence over the success of disaster management measures. This paper focuses on the improvement of the interaction in disaster management by designing change-capable protection systems. The corresponding project is funded by the EU-programme "Prevention, Preparedness and Consequence Management of Terrorism and other Security Related Risks". The Ministry of Interior of the Federal State of Brandenburg started this project in cooperation with the University of Potsdam, a chemical plant and the Public Fire Brigade of the West Pomeranian Voivodeship (Poland).

Change Capability describes the ability of a system to conform quickly and efficiently on changing requirements [1]. The need for changes and suitable activities is provided by the system itself. In order to examine the Change Capability of critical infrastructures, indicators of Change Capability need to be applied on protection structures. Those indicators are scalability, modularity, availability, interoperability, self-organisation, self-similarity, structural analogy, redundancy, diversity and knowledge. Some of these indicators are already mentioned within disaster management research (see section 2.2). Nevertheless, no comprehensive concept for the role of Change Capability related to disaster management exists. Concerning the overall functioning of protection systems, focused have been given on the following questions:

- How can Change Capability of protection systems be quantified?

- Does Change Capability increase the power of protection systems?

To answer the questions above, two methods have been developed: firstly, a method to determine and enhance the Change Capability of protection systems and secondly, a method for the impact assessments for disasters and those for protection systems. The impact assessment functions as evaluation for the results of the Change Capability analysis. It can be proved to what extend changecapable protection systems relieve disaster effects.

\section{Theoretical principles}

The aim of a Change Capability (CC) analysis is to estimate the ability of a system to cope with future or past modifications in its environment. Is the system able to react appropriately to these modifications? Is there any need of growth or development to increase its Change Capability? The following section introduces the concept Change Capability. Subsequently, indicators for Change Capability are presented. The third section shows the role of impact assessment. To verify that $\mathrm{CC}$ increases the power of protection systems, the procedure for impact assessment is used. 


\subsection{Change capability}

The CC-analysis consists of three modules: method configuration, prospective $\mathrm{CC}$-analysis and retrospective CC-analysis (see figure 1).

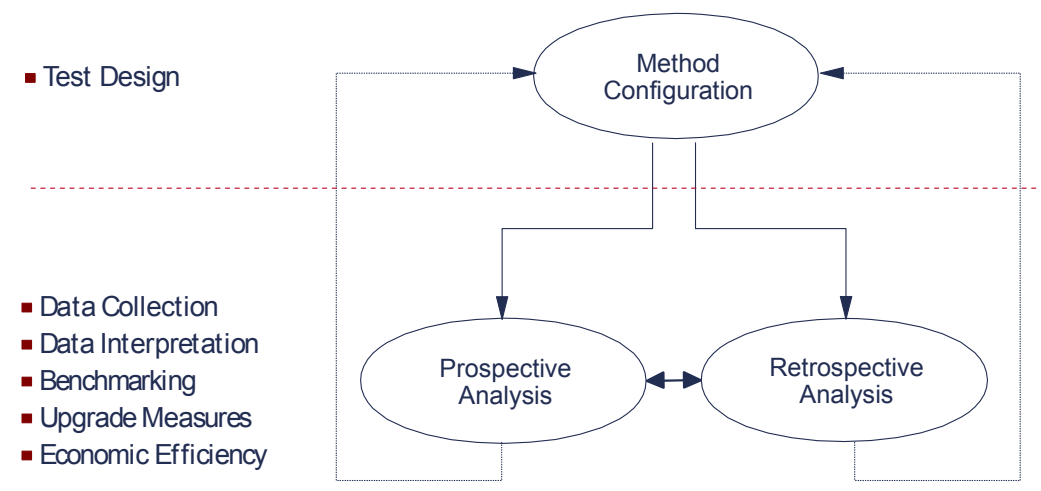

Figure 1: The modules of the change capability analysis.

The method is developed to improve and offer better results with each application. In the broader sense, the $\mathrm{CC}$ appropriateness of a system is depended on the estimation by experts. These empirical values are noticed and consulted if necessary for a further analysis. For method configuration, new application domains including scenarios, behaviour strategies or system specifications can be added at any time to the development cycle of the method.

In this project, the application domain is limited to protection concepts. Several emergency scenarios, such as the blackout of a filter plant for chemicals manipulation, were developed. Action strategies give different generic action patterns, by which a system can arrange itself with its environment. Examples are adaptation, mutation or stabilization. These strategies are based on characteristics of change-capable systems, such as scalability or redundancy. These characteristics presented below serve for each new CC-analysis as starter set (section 2.2) and can be weighted and even amended. Strategy applicability and characteristic relevance are raised both by expert estimates and by evaluation of the results of previous analyses.

The prospective analysis serves to determine the change-capability of a system before a concrete influence arises from outside. In the result can be specified, how strongly a system deviates from its possible CC. Coupled with economic efficiency calculation, the most effective and efficient strategies and strategy development measures can be identified. The prospective analysis is used for the current project.

The retrospective analysis deals with the behaviour of systems after an external influence. Which were the factors for the successful or hindering disaster management measures? Which CC-strategies were used, how effective and efficient were they and by what circumstances would their availability have 
been endangered? These empirical values flow in the module for method configuration (for example for the weighting of the CC-indicators).

\subsection{Change capability indicators}

In order to examine the Change Capability (CC) of critical infrastructures, indicators of $\mathrm{CC}$ are applied on protection structures. The following characteristics of self-adaptable systems are derived from both factory planning and natural systems. In the frame of factory planning, $\mathrm{CC}$ permits the modification and adaption throughout the system relating to its function, structure and hierarchy to implement a recognised need for change [2]. In the setting of enterprises, the term describes the demand of economic acting under continuously alternating and unpredictable conditions [3].

Scalability is an important attribute for systems to be self-adaptable, which is defined by its capacity characteristics [4]. This includes rules to integrate and extract resources, for example rescuers and tools.

Another indicator is modularity that allows reusing rescue modules in order to create a composition for new requirements [5].

The protection systems of critical infrastructures have to be available at anytime, including Sunday night and any place with no road accessibility. Consequently, the indicator availability includes mobility and temporal independency.

Interoperability increases the $\mathrm{CC}$ of systems. It focuses on communication rules, standardizing of formats and compatibility of system elements. The lack of common semantics is one of the problems concerning interoperability in disaster management [6].

Self-organisation is the crucial characteristic of natural systems that adapt to changing conditions. This indicator depends upon easy access to timely, accurate information through an information infrastructure that realises systematic monitoring of critical conditions, feedback to responsible actors, and revision of actions taken in the light of new information [7]. Therefore, during a disaster, the action force has to be informed on recent developments and must be able to pass information of their surroundings to others. Self-organisation is obviously related to knowledge. Knowledge enables the self-adaptable system to select the best possible way of adaption after environmental changes.

The indicators self-similarity and structural analogy comprise the similar essential structure of systems. Self-similarity concerns similarity within a system, no matter the selected degree of abstraction [3]. In contrast, structural analogy signifies that system elements of the same level are similar. As an example of the advantages, a unique design of disaster management systems shall be mentioned resulting in the easier ability to learn and efficiently use the system.

Furthermore, redundancy and diversity indicate self-adaptable systems. Since systems fail or recourses are already used, the multiple availability of system elements, like rescue workers or emergency vehicles, should be ensured. Diversity enables functions by use of different ways. For instance, the warning of the local residents could be done through the radio announcements or using the trucks that are equipped with loud speakers. 
These indicators are not absolutely completed. The set can be enhanced, reduced and differently weighted. It depends on the application domain and previous $\mathrm{CC}$ analyses. The indicators are operationalised by different questions (see section 3). By means of the measured values and their accumulation an index for $\mathrm{CC}$ can be generated. With a view to the deduction of upgrade measures the measured values have to be commented.

\subsection{Impact assessment}

The research results that relate to the improved $\mathrm{CC}$ of protection structures are evaluated by an impact assessment for disasters. This method is based on both technological and legal impact assessment. The latter one examines the necessity of legal regulation alternatives [8]. It focuses on consequences and effects of regulations. The technological impact assessment monitors and analyzes innovations in science and engineering [9]. The possibilities and risks with regard to social progress are explicitly taken into account.

The impact assessment for disasters is composed of six modules (see figure 2). Three modules configure every impact assessment for disasters and for protection systems. This ensures that protection systems can be evaluated by comparing the impacts of the same disaster, firstly by using the previous protection system and then followed by the new protection system.

\begin{tabular}{|l|l|l||}
\cline { 2 - 3 } \multicolumn{1}{l|}{} & Impact Assessment for Disasters & |A for Protection Concepts \\
\hline Prospective IA & Designing Disaster Scenarios & Designing Protection Concepts \\
\hline Inspective IA & $\begin{array}{l}\text { Checking the Disaster Scenarios } \\
\text { (probability of occurence, } \\
\text { damages) }\end{array}$ & $\begin{array}{l}\text { Checking and Testing the } \\
\text { Protection Concepts (aquisition of } \\
\text { expert knowledge, exercises) }\end{array}$ \\
\hline Retrospective IA & $\begin{array}{l}\text { Ascertaining Actual Consequences } \\
\text { and if necessary Adaption of the } \\
\text { Scenarios }\end{array}$ & $\begin{array}{l}\text { Ascertaining Actual Consequences } \\
\text { and if necessary Adaption of the } \\
\text { Protection Concepts }\end{array}$ \\
\hline
\end{tabular}

Figure 2: The modules of the impact assessment.

The prospective impact assessment is used to estimate impacts of various possible disaster types (assessment for disasters) or protection measures (assessment for protection systems). Inspective impact assessments focus on the selected disaster and protection operation. In the end, the retrospective impact assessment analyzes the impacts of an actually occurred disaster. These six modules can be individually applied. Each module consists of three phases [8]. Figure 3 below shows the prospective impact assessment phase: 
The method or method combination used for impact investigation is determined within the preparation phase. This will include issues such as expenses, involvement of experts and affected persons, scheduling and the degree of public attention. Collecting and analyzing disaster impacts can be realized by various methods as presented below. The method selection depends mainly on the availability of resources. An appropriate method to assess disaster impacts is drawing historical analogies, where the disaster scenario is compared with past runs of similar disasters [9]. Reliable and extensive information is fundamental to this method. Another alternative is the morphological method, where all attributes and forms of impacts are fanned out systematically to derive every thinkable disaster consequences. In respect of a practicable application, this needs a small group of participants. Scenario designing (best case, worst case, trend scenario) and the Delphi technique are also suitable for impact assessments. The combination of multiple methods increases the chance for realistic results. The above-mentioned procedure for impact assessment is very scalable. Thus, it can be used in various situations, as the case may be. Within the current project, the methods drawing historical analogies and table top exercises are applied. The exercises are also aiming to improve the cooperation of all parties involved in civil protection and disaster management. A specific disaster scenario defines the initial position of the exercise. Various events create a high demands on the protection systems, especially on its change capability. By comparing the impacts of these events relating to the status quo of the protection system and to the improved protection system, the positive influence of change-capability are able to be verified.

Table 1: $\quad$ Prospective impact assessment phase.

\begin{tabular}{|l|l|}
\hline Phase & Work Stages \\
\hline Preparation & $\begin{array}{l}\text { Definition and analysis of the possible disaster area } \\
\text { Collection of disaster types } \\
\text { Design of scenarios (instances of the disaster types) } \\
\text { Determination of adequate methods }\end{array}$ \\
\hline Implementation & $\begin{array}{l}\text { Workshops with experts and affected people or organizations } \\
\text { Review and where required modification of disaster } \\
\text { scenarios } \\
\text { Estimation of the disaster impacts }\end{array}$ \\
\hline Evaluation & $\begin{array}{l}\text { Summarizing and documentation of the results } \\
\text { Selection of one disaster type }\end{array}$ \\
\hline
\end{tabular}

\section{Project results}

The project is ongoing, first results are presented in this paper. The scope of the $\mathrm{CC}$ analysis concerns on the administration structure which is responsible for the chemical plant as a critical infrastructure. This scope constitutes the so-called protection system and includes public authorities, rescue resources (workers, tools and vehicles) as well as information and communication systems. Beside 
Table 2: $\quad$ Selected results of the CC-analysis.

\begin{tabular}{|c|c|}
\hline CC-Indicator & Estimation extracts \\
\hline Scalability & $\begin{array}{l}\text { A regional coordinating office will inform all other } \\
\text { relevant authorities. If the officer-in-charge orders } \\
\text { some more action forces or operating resources } \\
\text { during the rescue operation, the scheduler of the } \\
\text { coordinating office has to organise that. In case of a } \\
\text { disaster, the Ministry is explicit mandated to } \\
\text { establish a disaster control management. If needed, } \\
\text { the Ministry will inform other Federal States and } \\
\text { ask for rescue resources. The integration of new } \\
\text { resources is well-ordered, but there are no adequate } \\
\text { rules for the reduction. }\end{array}$ \\
\hline Modularity & $\begin{array}{l}\text { There are five regional coordinating offices within } \\
\text { the considered Federal State. On the level of the } \\
\text { action forces, it is not adequately possible to create } \\
\text { modules for specific scenarios. }\end{array}$ \\
\hline Availability & $\begin{array}{l}\text { Specific professionals (e.g. from environmental } \\
\text { department) are available } 24 \text { hours, seven days } \\
\text { every week. Further specialists are possibly not } \\
\text { immediately available. }\end{array}$ \\
\hline Interoperability & $\begin{array}{l}\text { Taking the federal structure of Germany into } \\
\text { account, each German Federal State has legislative } \\
\text { power for the sector of disaster protection. Terms } \\
\text { and definitions are not matched. } \\
\text { In case of a disaster the Minister of the Interior } \\
\text { (Federal State) takes the leadership together with the } \\
\text { head of the district authority. According to the law, } \\
\text { it is possible to alienate or attract the authority. } \\
\text { However, the law does not stipulate in what } \\
\text { circumstances which authority may exercise this } \\
\text { right. Thus, there exist no detailed rules for co- } \\
\text { operation. } \\
\text { Usually, the disturbance or the disaster is announced } \\
\text { by a special keyword via a so called immediately } \\
\text { fax. The keywords are not totally standardised } \\
\text { neither for whole Germany nor for Europe. } \\
\text { Standardization is guaranteed only within the region } \\
\text { for which the coordinating office takes } \\
\text { responsibility. }\end{array}$ \\
\hline Self-organization & $\begin{array}{l}\text { The officer-in-charge and the management of the } \\
\text { chemical factory cooperatively appreciate the risk } \\
\text { potential. }\end{array}$ \\
\hline
\end{tabular}


Table 2: $\quad$ Continued.

\begin{tabular}{|l|l|}
\hline CC-Indicator & Estimation extracts \\
\hline Knowledge & $\begin{array}{l}\text { The Ministry of Interior analyzes emergency black } \\
\text { spots. Each stakeholder individually prepares so } \\
\text { called "lessons learned". }\end{array}$ \\
\hline Diversity & $\begin{array}{l}\text { In case of a failure of the telephone system, the } \\
\text { scheduler and the sender will communicate via } \\
\text { BOS-net (radio network for public authorities and } \\
\text { organizations with security tasks) or even } \\
\text { annunciators (for example by motorcycle). }\end{array}$ \\
\hline
\end{tabular}

the organisations and systems, rescue processes are also considered. The results were achieved in close cooperation with a chemical plant and the responsible county disaster management authority who are involving both professionals and volunteers. Laws, disaster protection schedules and other official documents were analyzed to score the CC-indicators. Interviews and simulation (based on an emergency practice) account for the data collection within the $\mathrm{CC}$-analysis are also being done. Selected results are outlined in the following table.

To prepare the exercise for the CC-data collection a realistic scenario had to be acquired. Together with disaster management experts, a workshop was arranged to select and describe such a scenario. The time needed for this procedure step should not be underestimated. Interviews were necessary to complete the scenario characterization with regard to feasibility and relevance.

\section{Future prospects}

The above-mentioned results are not completed and more likely to show the idea of the procedure implementation. Further conclusions will be derived after the emergency exercise. Another issue in process is the weighting of the $\mathrm{CC}$ indicators. In all probability, the indicators have different consequences for the protection abilities of the defined scope. The Analytical Hierarchy Process (AHP) [10] will be used to identify the relevance of the single CC-indicators for both, project case and general protection systems of critical infrastructures. The pairwise comparison of the indicators constitutes the core of this method.

The conclusions of the $\mathrm{CC}$ analysis are evaluated by the impact assessment for protection systems. The same scenario as used in the emergency exercise will be the basis of the impact assessment (table top exercises). Interviews with the participants of the exercise will bring the needed data. By comparing the consequences of this incident the vantages of change-capable protection systems will be measurable. Finally, it is intended to transfer the developed procedures and derived conclusions to other application domains.

The indicators for $\mathrm{CC}$ are useful regarding to the design of protection systems. These characteristics empower protection systems to respond adequately to sudden events during a disaster. 


\section{References}

[1] Andresen, K., Gronau, N., Managing Change - Determining the Adaptability of Information Systems, EMCIS, 2006.

[2] Hernández, R., Wiendahl, H.-P.: Die wandlungsfähige Fabrik - Grundlagen und Planungsansätze. Erfolgsfaktor Flexibilität, Strategien und Konzepte für wandlungsfähige Unternehmen, ed. B. Kaluza, T. Blecker, Erich Schmidt Verlag: Berlin, pp. 203-227, 2005.

[3] Andresen, K., Gronau, N., Schmid, S., Ableitung von IT-Strategien durch Bestimmung der notwendigen Wandlungsfähigkeit von Informationssystemarchitekturen, Physica-Verlag: Heidelberg, pp. 63-82, 2005.

[4] Wall, F., Organisation und betriebliche Informationssysteme, Elemente einer Konstruktionslehre, Gabler: Wiesbaden, p. 164, 1996.

[5] Asghar, S. et al., A Dynamic Integrated Model for Disaster Management Decision Support Systems, International Journal of Simulation, 6(10-11), p. 97, 2005.

[6] National Research Council, Summary of a Workshop on Using Information Technology to Enhance Disaster Management, National Academics Press: Washington, D.C., p. 3, 2005.

[7] Koehler, G. A., (eds). What Disaster Respond Management Can Learn From Chaos Theory, Conference Proceedings, California Research Bureau, Sacramento, p. 118, 1996.

[8] Böhret, C., Konzedorf, G., Handbuch Gesetzesfolgenabschätzung, Nomos Verlagsgesellschaft: Baden-Baden, 2001.

[9] Baron, W., Grundfragen und Herausforderungen an eine partizipative Technikfolgenabschätzung. Technikfolgenabschätzung als politische Aufgabe, ed. R. Graf von Westphalen, Oldenbourg: München, pp. 137-158, 1997.

[10] Saaty, T.L., Vargas, L.G., Models, Methods, Concepts \& Applications of the Analytic Hierarchy Process, Kluwer Academic Publishers: Massachusetts, 2001. 